\title{
Governance, Transparency and the Collaborative Design of Open Data Collaboration Platforms: Understanding Barriers, Options, and Needs
}

\author{
Michael Hogan, Adegboyega Ojo, Owen Harney, Erna Ruijer, Albert Meijer, \\ Jerry Andriessen, Mirjam Pardijs, Paolo Boscolo, Elena Palmisano, \\ Matteo Satta, Jonathan Groff, Michael Baker, Françoise Détienne, \\ Lukasz Porwol, Vittorio Scarano, and Delfina Malandrino
}

\begin{abstract}
Developments in open data have prompted a range of proposals and innovations in the domain of governance and public administration. Within the democratic tradition, transparency is seen as a fundamental element of democratic governance. While the use of open government data has the potential to enhance transparency and trust in government, realising any ideal of transparent democratic governance implies responding to a range of sociotechnical design challenges.
\end{abstract}

M. Hogan $(\bowtie) \cdot$ O. Harney

National University of Ireland, Galway, Ireland

e-mail: michael.hogan@nuigalway.ie; o.harney2@nuigalway.ie;

http://www.linkedin.com/in/owenharney

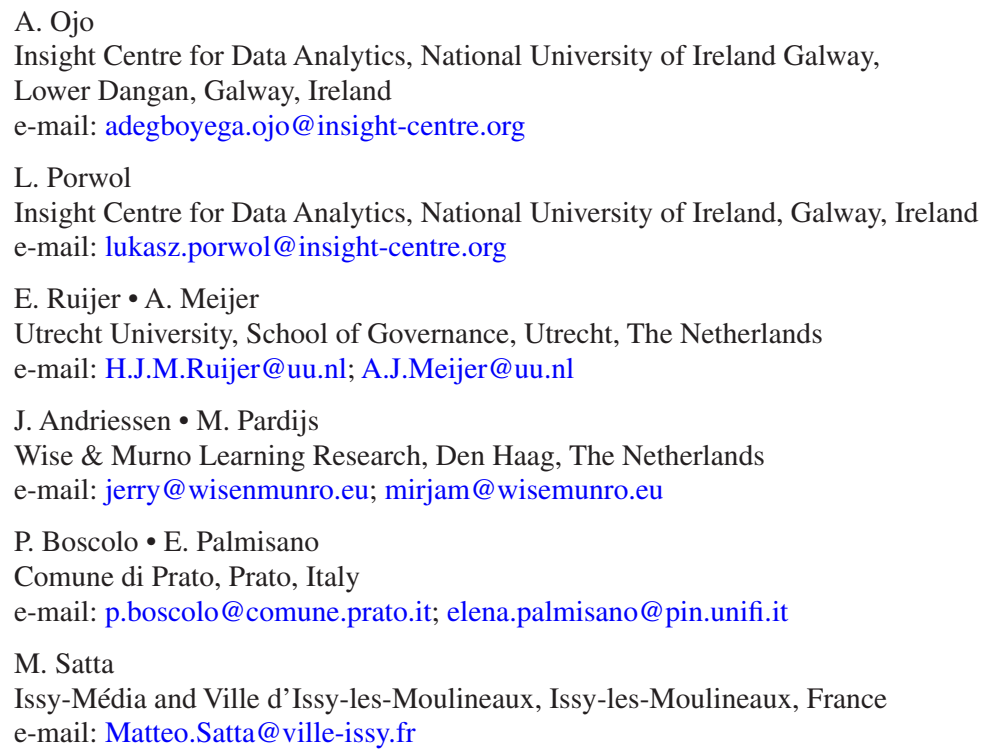


In order to address these design challenges it is essential to adopt an interdisciplinary and stakeholder-engaged approach to research and innovation. In the current study, we describe a contextualist approach to the design of an open data collaboration platform in the context of an EU innovation project, focused on enhancing transparency and collaboration between citizens and public administrators through the use of open government data. We report on a collective intelligence scenariobased design process that has shaped the development of open data platform requirements and ongoing system engineering and evaluation work. Stakeholders across five pilot sites identified barriers to accessing, understanding, and using open data, and options to overcome these barriers across three broad categories: government and organisational issues; technical, data, and resource issues; and training and engagement issues. Stakeholders also expressed a broad variety of user needs across three domains: information needs; social-collaborative needs; and understandability, usability, and decision-making needs. Similarities and differences across sites are highlighted along with implications for open data platform design.

Developments in political philosophy, science, technology, and open data information systems have prompted a range of proposals and innovations in the domain of governance and public administration. Within the democratic tradition transparency is seen as central to democratic governance (Ghaus-Pasha 2007) and has been a central focus of research and innovation in recent years (Meijer 2015a, 2015b). Advocates of open government and transparency have long argued that citizens should have the right to access the data, documents and proceedings of the government to allow for effective public scrutiny and oversight and to support increased public participation and collaboration (Habermas 1962; Bertot et al. 2008). Whether citizens are focused on monitoring government policy and the consequences of policy, deliberating and discussing policies and shaping the policy decision making process, or participating directly in policy development and public value creation, the use of open data which are available through platforms has the potential to enhance transparency and trust in government. The internet revolution and wide adoption of e-government across different parts of the world has made computermediated transparency a popular strategy for transforming transparency relationships between government and citizens towards greater co-creation and trust (Meijer 2009; Bannister and Connolly 2011). There are well over 8,000 datasets available on the European Union Open Data Portal (Ojo et al. 2016). This is in addition to

\footnotetext{
J. Groff • M. Baker • F. Détienne

CNRS - Telecom ParisTech, Paris, France

e-mail: jonathan.groff@telecom-paristech.fr; michael.baker@ telecom-paristech.fr;

francoise.detienne@telecom-paristech.fr

V. Scarano $\bullet$ D. Malandrino

University of Salerno, Fisciano (Salerno), Italy

e-mail: vitsca@unisa.it; dmalandrino@unisa.it
} 
hundreds of open data portals provided at different levels of government to enhance transparency and spur data-driven innovation.

While the availability of reliable open data on an open data platform can inform policies and practices in democratic societies, realising any ideal of transparent democratic governance implies a range of sociotechnical design challenges. These design challenges may vary depending on the political and social context and specific scenario of usage where open data is being used by stakeholders to address specific questions or problems. However, research on challenges and barriers to open data adoption has not focused much attention on specific scenarios or contexts of usage (Janssen et al. 2012; Attard et al. 2015; Meijer 2015a). The current study advances research in the area by adopting a collective intelligence scenario-based design approach to investigating the barriers to accessing, understanding, and using open data and the specific information, social-collaborative, and decision-making needs of stakeholders across a range of different open data usage scenarios. As part of an ongoing EU innovation project focused on the design of an open data collaboration platform, the current study presents the results of a series of collective intelligence scenario-based design workshops that have shaped the development of system requirements and ongoing system engineering and evaluation work. The results highlight a range of barriers to accessing, understanding, and using open data and a range of user needs that platform designers must consider based on specific scenarios across five pilot cases involving Local Authorities across four EU countries. Based on our results and experiences using the collective intelligence scenario-based design process, we argue that it is feasible to design open data platforms through a collaborative design process that engages key stakeholders. We further argue that open data platforms engineered this way will better meet stakeholders' needs in the context of real-world political and social scenarios.

\section{Approaching Design for Transparency: The Case for Contextualism}

Transparency is generally seen as a fundamental element of democratic governance (Ghaus-Pasha 2007). It is commonly associated with an entity's revelation or disclosure of information about its own decision processes, procedures, functioning and performance to external actors (Grimmelikhuijsen and Welch 2012). When transparency is conceived as a means to an end, transparency initiatives can have different goals ranging from limiting abuses of power, to tackling corruption, encouraging improved institutional performance and stimulating open innovation (Hilgers and Ihl 2010; Fox 2007).

Over the years, perspectives on, as well as treatment of transparency as a concept have evolved. Historically, two distinct eras of transparency have been identified transparency in an era of representative democracy and transparency in an era of participatory democracy (Meijer 2015b). While representative democracy is founded on the principle of elected officials representing a group of people, with the potential 
for people to monitor and discuss policies and policy outcomes, participatory democracy is a process emphasizing the broad participation of citizens and public administrators in the direction and operation of political systems and the co-creation of public value. The era of participatory democracy is associated with widespread availability of government documents and data on websites and open data portals (Meijer 2015b), which opens the potential not only to monitor government activity, but also deliberate and discuss policies in an informed manner, and participate and collaborate in the formulation of policy and the co-creation of public value.

Research and innovation in the area of transparency enhancing technologies emerges in parallel with different perspectives and conceptualisations of transparency. Different approaches to conceptualising transparency may influence open data platform and software design. Consistent with the collective intelligence design methods developed by Warfield (2006), which emphasise a stakeholder-driven approach to design, and consistent with the principles of scenario-based design (Caroll 2000), which emphasises the importance of understanding specific scenarios of usage in the technology design process, our view is that understanding the context of technology usage and the specific problems stakeholders are trying to resolve in context is important for the design of transparency-enhancing technologies. As such, we advocate contextualism as an orienting philosophy for conceptualising transparency and for understanding the technology-mediated activities that support transparency in context. In general, we believe that conceptualisations of transparency can be understood by reference to different worldviews, or ways of understanding reality, and different worldviews can influence the development of different frameworks shaping research, design, and innovation (Hayes et al. 1988). Drawing upon Pepper's (1942) distinction between formism, mechanism, organicism and contextualism, below we will briefly describe these worldviews in turn, and the rationale for adopting contextualism as an approach to technology design in the current project.

Formism, as defined by Pepper, involves the identification of forms, or aspects of reality, that share common or similar characteristics. Heald (2006) highlights a variety of different forms of transparency. For example, Heald (2006) draws a distinction between nominal versus effective transparency. While a nominal form of transparency might imply the availability of data on an open data platform, an effective form of transparency might involve data that is effectively used to shape valued outcomes (Heald 2006). Similarly, Heald (2006) distinguishes between forms of transparency that are based on an analysis of historical data (i.e., transparency in retrospect) and forms of transparency that are based on an analysis of data that reflects the current state of a system (i.e., transparency in real-time). As noted by Pepper (1942) identifying different forms, or aspects of reality, can be an important precursor to the development of more complex models, for example, mechanistic models that describe causal relationships between different aspects of reality. Similarly, formism may shape design thinking. For example, in the context of the design and innovation of an open data platform, formist conceptualisations of transparency may support design thinking in relation to specific aspects of technology design, related to specific forms of transparency. For instance, drawing upon a distinction between transparency in retrospect and transparency in real-time, a technology design team might include platform features that allow for a distinction to be 
made between current data and historical data, and possibly add prompts that help users to make these distinctions. At the same time, formist conceptualisations of transparency may limit design thinking in certain respects. While it might support design thinking in relation to specific forms of transparency, a formist approach to analysis does not generally emphasise a dedicated focus on activity in context. As such, a formist approach to understanding transparency may neglect key aspects of the context of transparency-related activities, or specific problem situations that involve interactions between stakeholders who analyse, discuss, and make use of open data in an effort to support transparency-related activities. In the absence of this more contextual focus distinctions between different forms of transparency may have limited value for the overall design of transparency-enhancing technologies.

In Pepper's (1942) scheme, a mechanistic worldview may build upon formist accounts by specifying how components parts of a system (or machine) work together. From this view, different forms of transparency may be viewed as different components of a system of interdependencies. For example, a mechanistic model may be developed to explain how components of transparency work together to produce trust in societies (Meijer 2009; Mei and Dewan 2014). Specific components of transparency such as visibility (the degree to which information is complete and easily located) and inferability (the degree to which information can be used to draw verifiable inferences) may in turn be influenced by other components of a system, and a mechanistic model of transparency may become increasingly complex as more components of reality are identified and modelled. For example, studies report that increased demand drives up visibility; and demand is strongest for issues that represent acute concerns of citizens, such as finance, health and security (Piotrowski et al. 2011). Although complex mechanistic models of transparency describing many component interdependencies can be developed to shed light on specific issues relevant for transparency-enhancing technology design, by virtue of their mechanistic structure, and the defined set of variables and components in the model, mechanistic models may constrain the ability of a design team to consider the varied actions and needs of users across different scenarios and contexts.

According to Pepper (1942), distinct from mechanism as a worldview is organicism. From the perspective of organicism transparency would be viewed as part of a living system that actively develops through various stages of maturity or functional complexity. For instance, the Transparency Maturity Model (Cappelli et al. 2013) characterises five levels of transparency - opaque, disclosed, comprehended, reliable, and participative. At the lowest level of maturity, the opaque level, the organization provides information access to the external environment in a non-systematic fashion. In the disclosed level, the organization provides information access to the external environment, but not necessarily in a way that is easily comprehended or responsive to feedback from external stakeholders. The comprehended level enables access to understandable information and thus facilitates a higher level of transparency and engagement. At the reliable level, the organization allows for auditability of the information provided. Finally, at the participative level the organisation allows for ongoing dialogue with the external environment about the information provided. As a worldview orientation, Pepper (1942) notes that organicism is linked to idealism, in the sense that there is an assumption that a system has the potential to develop 
toward a more ideal state of functioning. However, these idealist assumptions may not be aligned with the activity in context and thus by adopting organicism as a worldview, designers of transparency-enhancing technologies may neglect the problems and activities of technology users in context and thus fail to develop technologies that are well suited to the problems users are working to resolve.

As an approach to analysis and design, Pepper (1942) notes that contextualism emphasises a focus on activity in context. Contextualism allows for different strands of enquiry in relation to different activities in context, each of which may be important for successful workings, or the resolution of a specific problem in context. For example, a contextualist might consider the activities of key stakeholders seeking to access, understand, and use open data - the key barriers they face and the specific information, social-collaborative, and decision-making needs they have across different problem solving scenarios. In a participatory democracy scenario, where there is a focus on collaboration over open data in response to a specific political and social problem, one strand of contextualist enquiry might focus on the qualities of data, such as accessibility, usability, understandability, informativeness and auditability of the data (Cappelli et al. 2013). A related strand of analysis might focus on the social and organisational context within which data is sourced, including who the information holders are, the relevance of different types of public sector information, the availability of the information, and the distribution channels of information (Deloitte 2013). An analysis of these and related issues may be essential to the success of the participatory democracy group working together in the local problem situation. Notably, according to Pepper (1942), adopting the contextualist approach to research and innovation implies a focus on the specific purpose or goal(s) of actors in the problematic situation, and success is determined by the extent to which their purpose or goal(s) are achieved.

Given our focus on the design of a new open data platform, and our focus on developing system requirements that were matched to the context or scenario of usage identified across our pilot sites, we adopted a contextual and collective intelligence scenario-based approach to transparency research and innovation. Specifically, in the current study, we draw upon the collective intelligence scenariobased design thinking of stakeholders to define the scope of our analysis of open data transparency and our approach to the design of a new open data platform that may help to overcome barriers to accessing, understanding, and using open data and fulfil the key needs of stakeholders working across a variety of scenarios.

\section{Transparency Design and the Route-to-PA Project}

The research findings reported in this paper emerge as part of an ongoing EU innovation project, the "Route-to-PA" project (http://routetopa.eu/). Route-to-PA is focused on the design and evaluation of an open data collaboration platform that can be used by citizens and public administrators across a wide variety of usage scenarios. As the goal of the project is to design user-friendly transparency-enabling technologies for public administrations across a range of EU countries categorised 
by the Open Data Barometer $(2015)^{1}$ as high capacity (UK, France, and the Netherlands) and emerging and advancing (Italy and Ireland), it was important to understand the varied political and social contextswhere our design and innovation is to be realised. This involved an analysis of the open data readiness of each country, and a mapping of the local open data context for specific usage scenarios that reflect ongoing priorities of citizens and public administrations in each country (see http://routetopa.eu/wp-content/uploads/2016/07/D7.1_Market_analysis.pdf/). To maximize the socio-technical capabilities and vision of the design team, it was essential to engage with key stakeholders and users in each pilot site to understand the barrriers to accessing, understanding, andusing open data, options to overcome these barriers, and the key needs and requirements of users across a range of monitorial, deliberative, and participatory democracy scenarios. Furthermore, as the goal of the Route-to-PA project is the design of a flexible open data collaboration platform that allows for a range of democratic activities, up to and including collaboration and co-creation of public value, it was essential that the range of needs stakeholders specified in response to scenarios include not only information needs, but also social-collaborative and decision-making needs. In order words, the open data platform needed to allow for collaboration, shared learning, and decision making in the context of accessible, usable, understandable open data. As such, we approached our contextual analysis and system design work using an integrative collective intelligence scenario-based design approach. Below we describe our approach to system design in more detail and present the results of our study, highlighting in particular the range of barriers, options, and needs our stakeholders identified and how we have grounded our open data platform design in this collective intelligence work.

\section{Advancing Our Knowledge and Innovation Potential Using Collective Intelligence Scenario-Based Design}

While it is widely recognised that open data platforms can foster democratic processes by promoting transparency (Lourenço 2013; Dawes and Helbig 2010; Janssen 2011), researchers have identified a range barriers that hamper effective service design and the full potential of open data innovations. Barriers to effective service design in the area of open data include limited organizational resources and budget, legislative challenges, poor information quality, lack of usability and technical issues (Janssen et al. 2012; Attard et al. 2015; Meijer 2015a ). In working to overcome these barriers researchers have proposed a range of generic user requirements (Lourenço 2013; Jaeger et al. 2012; Van Velzen et al. 2009) and assessment frameworks for open data portals and policies (Sandoval-Almazan and Gil-Garcia 2012; Zuiderwijk and Janssen 2014; Lee and Kwak 2012). These approaches either

\footnotetext{
${ }^{1}$ Open Data Barometer (January 2015) - http://barometer.opendataresearch.org/
} 
take users (both citizens and government) or open data portals as point of departure for analysis. However, the unique context and scenarios of usage and the unique perspectives of stakeholders in relation to information, social-collaborative, and decision-making needs are less often considered in the literature and open data platform design process (Dahlander et al. 2009). Focusing on specific scenarios of usage and the specific needs of users may be important for adoption, uptake and use of open data and open data platforms.

At a basic level, effective computer-mediated transparency implies that external or receiving parties are capable of processing information that has been made available (Heald 2006). However, platforms for open-data enabled transparency are often limited in this regard. Literature on open data portal software shows that social media features are limited on existing or first generation open data portal software or platforms (Alexopoulos et al. 2014). Specifically, these platforms do not provide beyond features for sharing information about datasets on major social media platforms, thus limiting the potential use of open data in participatory democracy scenarios. In addition, features for checking compliance with metadata standards and good practices (Greiner et al. 2015) are very limited, thus limiting feedback from users to data providers that may enhance the quality of data published online. Understanding the unique perspectives of stakeholders and their unique scenarios of usage is critical for the design of platforms and platform software features that are responsive to user needs.

Central to our design work in the Route-to-PA project is the combination of collective intelligence (Warfield 2006) with scenario-based design (Caroll 2000) and agile user story (Cohn 2004) methods. Collective intelligence methods ensure input from a diverse range of representative stakeholders in the design process and the use of scenario-based design methods ensures that identified needs and requirements of users are grounded in an understanding of specific political and social scenarios that are relevant to stakeholders. Finally, the use of agile user stories allows for the specification of user needs, and reasons for those needs, at a level of detail that allows for agile software development of specific functionalities. Working across four EU countries and five pilot sites, we used these methods in a series of carefully designed workshops, one in each pilot site, for the purpose of developing a comprehensive set of user needs, as proposed by key stakeholders.

Each workshop brought together experts, academics, industry specialists, open data practitioners, representatives of governments, open data researchers, and potential users (including citizens, representatives of citizens and social service institutes, various stakeholder groups, and journalists) to reflect on (a) barriers to accessing, understanding and using open data, (b) options to overcome specific categories of barriers, and (c) specific user needs and requirements necessary for consideration in the design of the Route-To-PA platform. More specifically, based on John Warfield's (1994) science of design, in the first phase of each workshop, we used collective intelligence methodologies to understand barriers to accessing and using open data, and options to overcome these barriers. Participants then worked to develop scenario-based user needs (Rosson and Carroll 2002), which involved profiling user needs in light of the barriers and options and high level scenarios of 
open data usage. This included a separate focus on (1) information needs - what kinds of data do stakeholders want?; (2) social and collaborative interaction needs how do stakeholders want to use and interact with the data?; and (3) understandabilty, usability and decision-making needs - what kinds of decisions do stakeholders want to make with the data and how would they like to use the data? High level scenarios including multiple users were used to prompt idea writing and discussion in relation to user needs. The scenarios addressed various contextual issues, relevant to each workshop site, and aligned with the primary case focus and societal issue in each pilot site. For example, the Dublin workshop focused on community networking and opportunity creation; the Groningen workshop focused on the challenge of population decline; the Den Haag workshop focused on employment and opportunity creation; the Prato workshop focused on local policy and budget issues; and the workshop in Issy-les-Moulineaux focused on the facilitation of start-up companies and the digital economy. The research team conducted a meta-analysis of barriers, options, and needs across all sites and used this analysis to inform the specific usecase models and system requirements for the Route-to-PA platform. Below we describe these methods and our results in more detail.

\section{Method and Results}

\section{Scenarios and Pilot Sample Details}

A total of 83 workshop participants across the five sites participated in the study. Participants represented a broad variety of stakeholders with stakeholder representation distributed evenly across sites. Participants included representatives of stakeholder groups, business representatives, NGO representatives, public administrators and other government representatives, data experts, developers, and researchers. See Fig. 1 for a breakdown of stakeholders across sites.

\section{Workshops}

Each pilot site ran a workshop following a common method. The workshop began with a collective intelligence (CI) analysis of barriers to accessing, understanding and using open data, followed by an analysis of options that may overcome these barriers. Based on Warfield's (1994) science of generic design, the CI process is a facilitated problem solving methodology that helps groups to develop outcomes that integrate contributions from individuals with diverse views, backgrounds, and perspectives. Established as a formal system of facilitation in 1980 after a developmental phase that started in 1974, CI was designed to assist groups in dealing with complex issues. The CI approach carefully delineates content and process roles, assigning to participants responsibility for contributing ideas and to the facilitator 


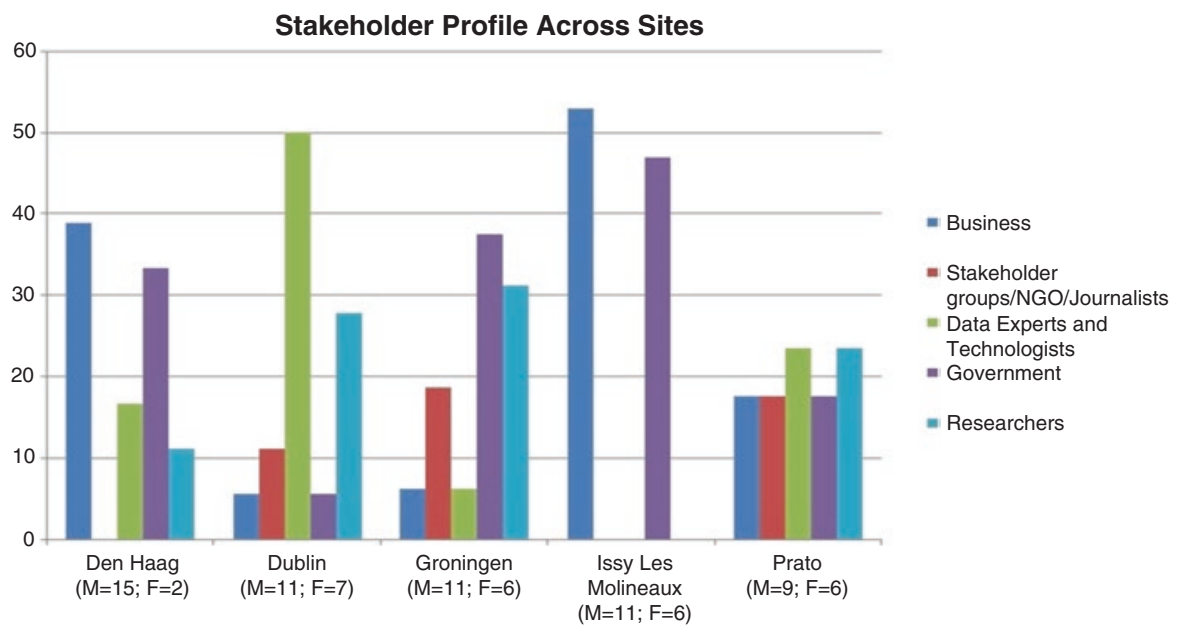

Fig. 1 Stakeholder profile across sites

responsibility for choosing and implementing selected methodologies for generating, clarifying, structuring, interpreting, and amending ideas. Emphasis is given to balancing behavioural and technical demands of group work (Broome and Chen 1992) while honouring design laws concerning variety, parsimony, and saliency (Ashby 1958). CI has been applied in a variety of situations to accomplish many different goals, including assisting city councils in making budget cuts (Coke and Moore 1981), developing instructional units (Sato 1979), designing a national agenda for paediatric nursing (Feeg 1988), creating computer-based information systems for organizations (Keever 1989), improving the U.S. Department of Defense's acquisition process (Alberts 1992), promoting world peace (Christakis 1987), improving Tribal governance process in Native American communities (Broome and Cromer 1991), and training facilitators (Broome and Fulbright 1995). CI has also been recently used in a variety of basic science applications, for example, to design a national well-being measurement system (Hogan et al. 2015), to understand the adaptive functions of music listening (Groarke and Hogan 2016), and to design a student-centred conceptualisation of critical thinking (Dwyer et al. 2014).

CI utilizes a carefully selected set of methodologies, which may include the nominal group technique, ideawriting, interpretive structural modelling, and field and profile representations. The methodologies are matched to the phase of group interaction and the requirements of the situation. For the purposes of idea generation in our workshops, the ideawriting technique was used, along with categorisation or field representation of ideas. Ideawriting is a method that utilizes relatively small groups of 4-6 persons each, formed by dividing a larger group into several working teams, for the purpose of developing ideas and exploring the meaning of those ideas through open discussion (Warfield 1994). Ideawriting involves five steps: (a) presentation of a stimulus question to participants; (b) silent generation of ideas in writing by each participant working alone; (c) exchange of written sheets of ideas among all group members, 
with opportunity for individuals to add ideas as they read others' papers; (e) discussion and clarification of unique ideas; and (f) an oral report of the ideas generated by each working group in a plenary session. In this plenary session, duplicate ideas across the working groups are eliminated from the set and new ideas are added; the resulting set of ideas is then ready for use in the next stage of the group's work.

In the current application of CI, workshop participants first engaged in ideawriting in response to the question:

"What are barriers to accessing, understanding and using Open Data?"

Each workshop generated a set of barriers, which were thematically arranged into categories using a paired comparison method to create a field representation of clusters of related ideas (for more details, see RezaeiZadeh et al. 2017; Warfield 2006). Next, workshop participants engaged with these categories to generate options for overcoming barriers. This was done by means of another round of ideawriting and discussion. In the third phase of the workshop, participants documented scenario-based user needs, by means of agile user stories. This involved profiling user needs in light of the barriers and options and high level scenarios of open data usage (see Table 1 for an overview of scenarios; see appendix 1 for sample scenarios). This included a separate focus on (1) information needs, (2) social/ collaborative interaction needs, and (3) understandabilty, usability and decisionmaking needs. Idea writing was used for each cluster of needs. High level scenarios including multiple users were used to prompt thinking in relation to user needs. All the agile user stories generated by participants were generated in the form:

As User Type I want so that I can

Participants were asked to consider the roles and needs of the different actors in each scenario, and generate a list of needs for each actor. Ideas were subsequently discussed by sub-groups and all ideas and handouts were then gathered and collated by the workshop facilitation team. Each pilot site facilitation team conducted an analysis of needs by categorising related needs within each of the three domains (i.e., information, social/collaborative interaction needs, and understandabilty, usability and decision-making) and documenting the frequency of needs in each category. These analyses are reported in detail in an EU report published online here: http:// routetopa.eu/wp-content/uploads/2015/06/D2.3_-User_stories_on_Open_Data_and_ Transparency-v1.0.pdf. The research team engaged in a further meta-analysis of barriers, options, and needs across all sites. The results of this analysis are reported below.

\section{Barriers to Accessing, Understanding, and Using Open Data, and Options for Overcoming These Barriers}

Figure 2 below presents the results of a relative frequency analysis of barriers to accessing, understanding, and using open data across sites, with the total number of barrier statements in each category noted in the legend. A set of 12 categories were 
Table 1 Scenarios

\begin{tabular}{|c|c|c|c|}
\hline Pilot & Context & Actors involved & Use of open data in scenarios \\
\hline Dublin & $\begin{array}{l}\text { Deliberative } \\
\text { Democracy; } \\
\text { Participatory } \\
\text { Democracy }\end{array}$ & $\begin{array}{ll}\text { - } & \text { Public } \\
& \text { Administrator } \\
\text { - } & \text { Entrepreneur } \\
\text { - } & \text { Citizen } \\
\text { - } & \text { Local Activist } \\
\text { - } & \text { Local Group } \\
& \text { Coordinator } \\
\text { - } & \text { Civic Hacker } \\
\end{array}$ & $\begin{array}{l}\text { - } \text { Societal Issues } \\
\text { - Improved Govemment } \\
\text { financial efficiency } \\
\text { - } \text { Business development } \\
\text { - Community building } \\
\text { - Citizen-Government } \\
\text { communication }\end{array}$ \\
\hline Groningen & $\begin{array}{l}\text { Deliberative } \\
\text { Democracy; } \\
\text { Participatory } \\
\text { Democracy }\end{array}$ & $\begin{array}{ll}\text { - } & \text { Principal } \\
\text { - } & \text { Public } \\
\text { - Administrator } \\
\text { - Community } \\
\text { Activist } \\
\text { - Entrepreneur } \\
\text { - Local Business } \\
\text { Community } \\
\text { - Local Community } \\
\text { Members }\end{array}$ & $\begin{array}{l}\text { - Government actions } \\
\text { monitoring and } \\
\text { collaboration } \\
\text { - Business community } \\
\text { collaboration }\end{array}$ \\
\hline Den Haag & $\begin{array}{l}\text { Deliberative } \\
\text { Democracy; } \\
\text { Participator } \\
\text { Democracy }\end{array}$ & $\begin{array}{ll}\text { - } & \text { Public } \\
& \text { Administrator } \\
\text { - } & \text { Business Owner } \\
\text { - } & \text { Citizen } \\
\text { - } & \text { Unemployed } \\
\text { - } & \text { Entrepreneur } \\
\text { - } & \text { Disabled Job } \\
& \text { Seeker } \\
\end{array}$ & $\begin{array}{l}\text { Social problem solving- } \\
\text { unemployment of disabled }\end{array}$ \\
\hline Prato & $\begin{array}{l}\text { Monitorial } \\
\text { Democracy, } \\
\text { Deliberative } \\
\text { Democracy; }\end{array}$ & $\begin{array}{ll}\text { - } & \text { Public } \\
& \text { Administrator } \\
\text { - } & \text { Student } \\
\text { - } & \text { Citizen } \\
\text { - } & \text { Community } \\
& \text { Activist } \\
\text { - } & \text { Journalist } \\
\text { - } & \text { Accountant }\end{array}$ & $\begin{array}{l}\text { - } \text { Citizen-Government } \\
\text { communication } \\
\text { - Inclusive policy making } \\
\text { - Citizen collaboration and } \\
\text { co-creation } \\
\text { - Service improvement } \\
\text { - } \text { Government actions } \\
\text { monitoring }\end{array}$ \\
\hline $\begin{array}{l}\text { Issy-les- } \\
\text { Moulineaux }\end{array}$ & $\begin{array}{l}\text { Deliberative } \\
\text { Democracy, } \\
\text { Participatory } \\
\text { Democracy }\end{array}$ & $\begin{array}{ll}\text { - } & \text { Entrepreneur } \\
\text { - Local Community } & \text { Members } \\
\text { - } & \text { Businesses } \\
\text { - } & \text { Public } \\
\text { - Administrator } \\
\text { - Domain Expert }\end{array}$ & $\begin{array}{l}\text { Social problem solving- } \\
\text { ecology, technology, and } \\
\text { mobility services }\end{array}$ \\
\hline
\end{tabular}

identified by two interdependent coders using the paired comparison method (Warfield 2006). These included a number of categories of barriers related to government and organisational issues, such as: Conflict and Cooperation; Government and Organisational: Resistance to Open Data Initiatives; Government and Organisational: Fear of Losing Control of Data; and Privacy and Security. Another set of barrier categories were linked to technical, data, and resource issues, specifically: Data Applications; Data Management/Policies; Data Quality, Accessibility, 


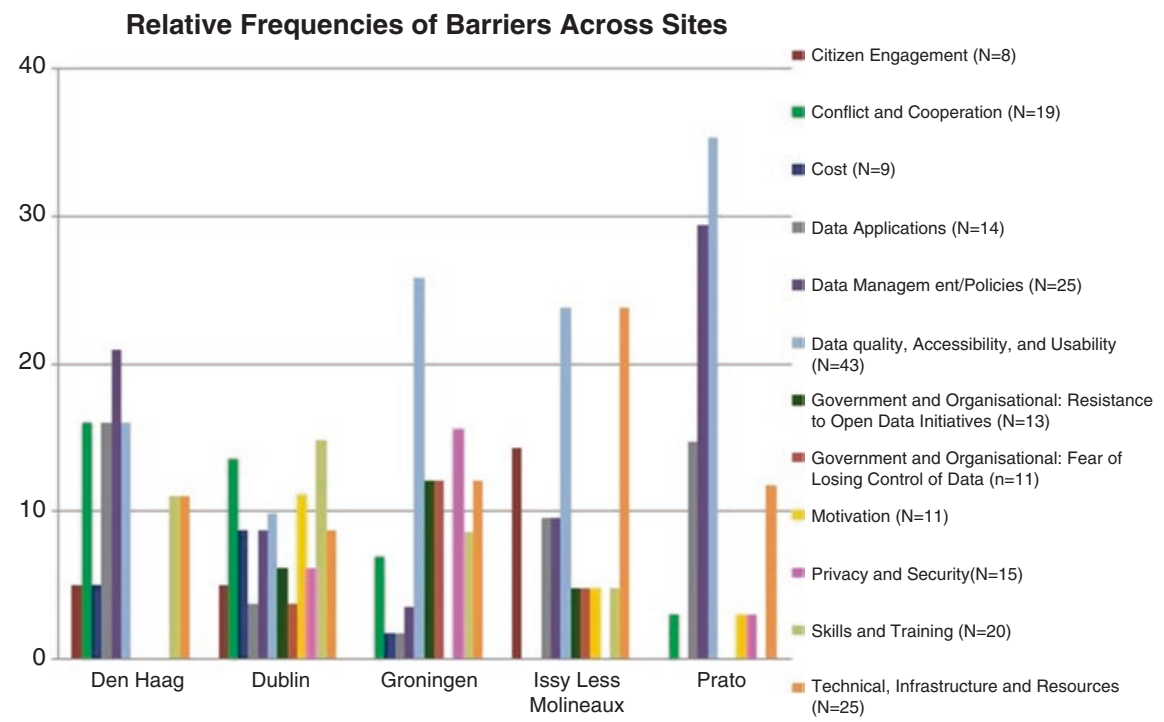

Fig. 2 - Relative frequencies of barriers across sites

and Usability; Technical, Infrastructure and Resources; and Cost. Finally, a set of barrier categories related to training and engagement issues, including: Citizen Engagement; Skills and Training; and Motivation. Table 2 presents a sample of barriers from each category.

The frequency analysis - that is, an analysis of the number of barrier statements generated by each site across the 12 categories, controlling for the total number of ideas generated in each site - allows for comparison of the relative weight stakeholders in each pilot site placed on the various barrier categories. Looking at Fig. 2, it can be seen, for example, that $35 \%$ of all barriers generated in Prato related to Data Quality, Accessibility, and Usability. As such, this category accounted for the highest percentage of total barriers generated by stakeholders in Prato. Looking across the pilot sites, it is also evident that the category Data Quality, Accessibility, and Usability accounted for the highest or joint-highest percentage of total barriers in Groningen, Issy-les-Moulineaux, and Den Haag.

\section{Options to Overcome Categories of Barriers}

Table 2 also presents a sample of options generated by participants, linked to specific barriers. Notably, a large proportion of options across sites related to efforts to respond proactively and positively to government and organisational resistance, which may be seen as central to enhancing overall open data infrastructures and practices. Furthermore, a large portion of options across sites focused on the need for skills and training, citizen engagement, and efforts to enhance data quality and usability. 
Table 2 - Categories of barriers and options across sites, including samples

\begin{tabular}{|c|c|c|}
\hline Categories of barriers & Sample barriers & Sample options \\
\hline \multirow[t]{2}{*}{ Citizen Engagement } & $\begin{array}{l}\text { Failure by government } \\
\text { departments to advertise that } \\
\text { datais available to the public }\end{array}$ & $\begin{array}{l}\text { Open a channel for the public } \\
\text { to communicate with } \\
\text { governments }\end{array}$ \\
\hline & $\begin{array}{l}\text { Minimal publicity about data } \\
\text { available leading to lack of } \\
\text { awareness of its existence }\end{array}$ & $\begin{array}{l}\text { Put good examples in the } \\
\text { limelight (competent } \\
\text { citizens) }\end{array}$ \\
\hline \multirow[t]{2}{*}{ Conflict and Cooperation } & $\begin{array}{l}\text { Conflict between wanting to } \\
\text { share data and the data being } \\
\text { used as criticism }\end{array}$ & $\begin{array}{l}\text { Establish an open data } \\
\text { training officer or advisor } \\
\text { within an organisation }\end{array}$ \\
\hline & $\begin{array}{l}\text { Conflict between privacy and } \\
\text { openness }\end{array}$ & $\begin{array}{l}\text { Encourage a code of conduct } \\
\text { that allows fair discussion } \\
\text { and not vindictive trolling }\end{array}$ \\
\hline \multirow[t]{2}{*}{ Cost } & $\begin{array}{l}\text { Inadequate finances to fund } \\
\text { the sustained collection and } \\
\text { sharing of open data }\end{array}$ & $\begin{array}{l}\text { Data creation should be } \\
\text { driven by user demand }\end{array}$ \\
\hline & $\begin{array}{l}\text { The cost of accessing data } \\
\text { may be prohibitive }\end{array}$ & $\begin{array}{l}\text { Centralize streamline formats } \\
\text { license metadata for all } \\
\text { datasets from all sources }\end{array}$ \\
\hline \multirow[t]{2}{*}{ Data Applications } & $\begin{array}{l}\text { Lack of examples available } \\
\text { for smart use of open data }\end{array}$ & $\begin{array}{l}\text { Make a connection with } \\
\text { education }\end{array}$ \\
\hline & $\begin{array}{l}\text { Scarce effectiveness of } \\
\text { research tools: queries are } \\
\text { not tailored on real users } \\
\text { needs }\end{array}$ & $\begin{array}{l}\text { More complete platform for } \\
\text { better search ability of data }\end{array}$ \\
\hline \multirow[t]{2}{*}{ Data Management/Policies } & $\begin{array}{l}\text { Lack of information about } \\
\text { the circumstances of data } \\
\text { production }\end{array}$ & $\begin{array}{l}\text { Set up good information } \\
\text { management practices across } \\
\text { all public bodies - data } \\
\text { co-ordinates }\end{array}$ \\
\hline & Lack of data maintenance & $\begin{array}{l}\text { Regulate Transparency from } \\
\text { all sides (policy making, } \\
\text { showcase it. budgets): reward } \\
\text { it }\end{array}$ \\
\hline \multirow[t]{2}{*}{$\begin{array}{l}\text { Data Quality, Accessibility, and } \\
\text { Usability }\end{array}$} & $\begin{array}{l}\text { Data is published but cannot } \\
\text { be found and does not have a } \\
\text { user-friendly format }\end{array}$ & $\begin{array}{l}\text { Involve users in the } \\
\text { development of the platform }\end{array}$ \\
\hline & Insufficient data description & $\begin{array}{l}\text { Be clear about what is what: } \\
\text { when collected, by whom. } \\
\text { how. and so on }\end{array}$ \\
\hline $\begin{array}{l}\text { Government and } \\
\text { Organisational: Fear of Losing } \\
\text { Control of Data }\end{array}$ & $\begin{array}{l}\text { Fear of how transparency via } \\
\text { open data might affect the } \\
\text { organisation } \\
\text { Fear of misuse of data }\end{array}$ & $\begin{array}{l}\text { Explain what open data is } \\
\text { Facilitate a culture change: it } \\
\text { is ok to make mistakes, } \\
\text { political backup for } \\
\text { management }\end{array}$ \\
\hline
\end{tabular}


Table 2 (continued)

\begin{tabular}{|c|c|c|}
\hline Categories of barriers & Sample barriers & Sample options \\
\hline $\begin{array}{l}\text { Government and } \\
\text { Organisational: Resistance to } \\
\text { open data initiatives }\end{array}$ & $\begin{array}{l}\text { Failure to understand the } \\
\text { organisational benefits of } \\
\text { releasing open data } \\
\text { It will take a lot of effort to } \\
\text { convince people to use open } \\
\text { data }\end{array}$ & $\begin{array}{l}\text { Demonstrate the business } \\
\text { case to local governments } \\
\text { through case studies, } \\
\text { feedback and further } \\
\text { innovation outcomes } \\
\text { Support and drive } \\
\text { organisational change } \\
\text { programs; Organisational } \\
\text { change management is } \\
\text { essential. }\end{array}$ \\
\hline \multirow[t]{2}{*}{ Motivation } & $\begin{array}{l}\text { Failure to understand the } \\
\text { benefits that Open Data can } \\
\text { offer }\end{array}$ & $\begin{array}{l}\text { Identify and publish data that } \\
\text { is relevant and engaging }\end{array}$ \\
\hline & $\begin{array}{l}\text { Data publishing is not } \\
\text { perceived as a "mission" in } \\
\text { administration's point of } \\
\text { view' }\end{array}$ & $\begin{array}{l}\text { Promote the benefits of an } \\
\text { open data portal and give } \\
\text { good examples }\end{array}$ \\
\hline \multirow[t]{2}{*}{ Privacy and Security } & $\begin{array}{l}\text { Personal information } \\
\text { accessed by public canlead } \\
\text { to data protection } \\
\text { infringement }\end{array}$ & $\begin{array}{l}\text { Very clear data protocol and } \\
\text { guidance }\end{array}$ \\
\hline & $\begin{array}{l}\text { Some data is commercially } \\
\text { sensitive }\end{array}$ & $\begin{array}{l}\text { Profiling of platform } \\
\text { members could support their } \\
\text { research without violating } \\
\text { personal information or } \\
\text { property rights }\end{array}$ \\
\hline \multirow[t]{2}{*}{ Skills and Training } & $\begin{array}{l}\text { Inadequate technical } \\
\text { expertise to produce data in a } \\
\text { usable format }\end{array}$ & $\begin{array}{l}\text { Provide information, training } \\
\text { and education, for all } \\
\text { government agencies on the } \\
\text { benefits of an open data } \\
\text { portal }\end{array}$ \\
\hline & $\begin{array}{l}\text { Users lack the skills to } \\
\text { process data and translate } \\
\text { into information }\end{array}$ & $\begin{array}{l}\text { Provide open data FAQs for } \\
\text { basic users }\end{array}$ \\
\hline $\begin{array}{l}\text { Technical, Infrastructure, and } \\
\text { Resources }\end{array}$ & $\begin{array}{l}\text { Data is spread over different } \\
\text { organizations and } \\
\text { departments } \\
\text { Inadequate institutional } \\
\text { capacity to provide open data } \\
\text { services, to develop } \\
\text { standards and to provide } \\
\text { expertise }\end{array}$ & $\begin{array}{l}\text { Pooling of public sector } \\
\text { resources } \\
\text { Better curation and } \\
\text { maintenance of data quality }\end{array}$ \\
\hline
\end{tabular}

As was the case with regard to barriers, there were also differences in the relative frequencies of options across sites. For example, while the Technical, Infrastructure and Resources category accounted for a high percentage of total options generated in Den Haag and Issy-les-Moulineaux, fewer options were generated in response to this category in the other sites. Similarly, while Citizen Engagement received a high 


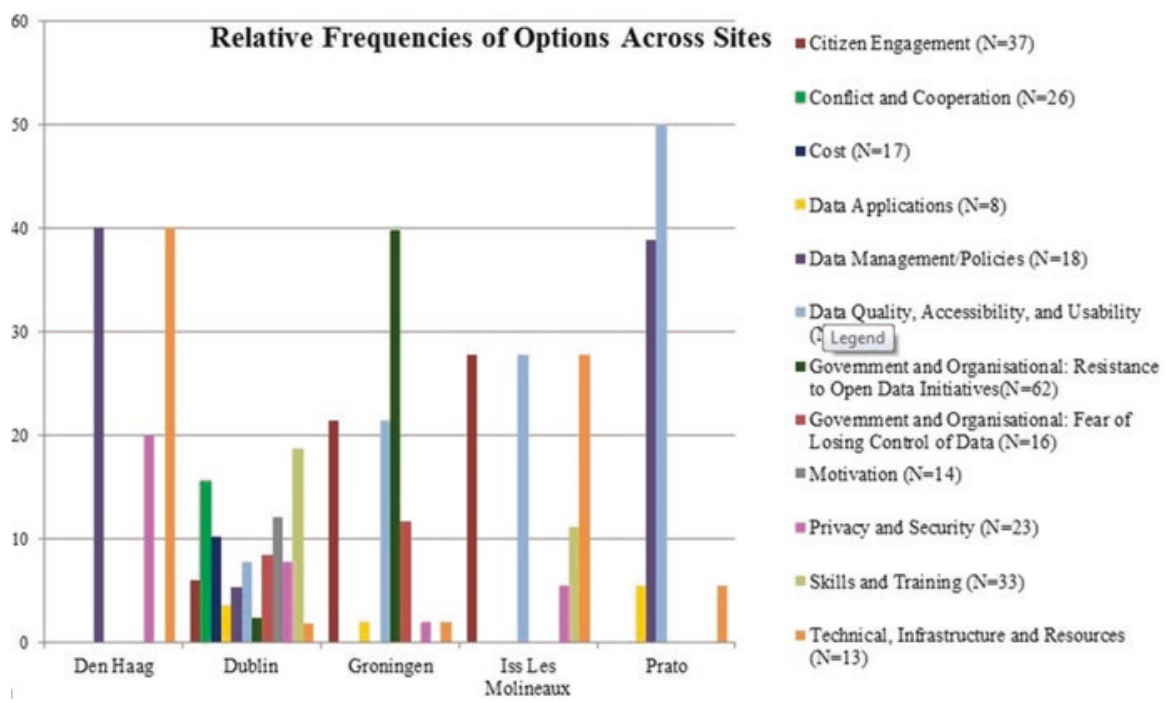

Fig. 3 Relative frequencies of options across sites

percentage of generated options in Groningen and Issy-les-Moulineaux, it received less attention in the other sites. Also, whereas options in Dublin were spread across all categories, options were more focused on a smaller set of specific categories in Den Haag and Prato. This suggests that, from the perspective of stakeholders, these pilot sites, at least in their initial evaluation of the problem situation, have identified a particularly strong need for options to overcome barriers for a select number of categories (Fig. 3).

\section{User Needs}

\section{Information Needs}

Stakeholders also highlighted specific needs of users in light of specific scenarios of usage. Table 3 presents sample information needs for each category.

Given the range of scenarios, the user information needs generated across sites were numerous and diverse, allowing for interesting comparisons (see Fig. 4). For example, while the focus of the Den Haag workshop was on employment and opportunity creation, resulting in a high proportion of information needs being developed under the category Jobseekers Information, the Dublin workshop, which focused on community engagement and planning generated information needs across a much wider range, including: Community Information; Planning Information; Services, Amenities and Event Information; Business and Financial Information; and Child and Education-related. Also of note, for example, is the high percentage of needs devoted to Business and Financial Data, in two pilot 
Table 3 Sample information needs across sites

\begin{tabular}{|c|c|}
\hline Categories of information needs & Sample needs \\
\hline Broadband Data & $\begin{array}{l}\text { It is important to know where broadband internet is available } \\
\text { if you want to start up your own business } \\
\text { Fast internet to know whether I can work from home }\end{array}$ \\
\hline Business and Financial Data & $\begin{array}{l}\text { Access to economic data } \\
\text { To find out about local business rates in the area }\end{array}$ \\
\hline Child and Education-related & $\begin{array}{l}\text { Projection of the amount of students for the coming } 10 \text { years } \\
\text { Knowing what the future of the school will be so that I can } \\
\text { make plans for the future of the children }\end{array}$ \\
\hline Community Information Needs & $\begin{array}{l}\text { A list of community groups and different types of } \\
\text { communities in the city } \\
\text { Data to provide me with new insights on mv community }\end{array}$ \\
\hline Contact Information & $\begin{array}{l}\text { Where and with whom can I talk about e.g. education policy } \\
\text { Contact with government }\end{array}$ \\
\hline Demographic Information & $\begin{array}{l}\text { Birth rates and migration rates } \\
\text { Population statistics }\end{array}$ \\
\hline Government Role/Transparency & $\begin{array}{l}\text { To know what the government and city are doing about } \\
\text { population decline in education } \\
\text { To get information about Open Data set traceability }\end{array}$ \\
\hline Health Data & $\begin{array}{l}\text { Available data about health services in my village } \\
\text { Information regarding health services and support facilities }\end{array}$ \\
\hline Jobseeker Information & $\begin{array}{l}\text { Overview of regulations } \\
\text { Standardised CV templates }\end{array}$ \\
\hline Legal and Policy Data & $\begin{array}{l}\text { Information about laws and regulations, like zoning } \\
\text { Data on European community legislation }\end{array}$ \\
\hline $\begin{array}{l}\text { Market Developments: Housing } \\
\text { Data }\end{array}$ & $\begin{array}{l}\text { Information of the last } 20 \text { years to examine whether there is } \\
\text { indeed a housing dip } \\
\text { Housing value data }\end{array}$ \\
\hline Planning Data & $\begin{array}{l}\text { Information relating to developmental programmes } \\
\text { Local news, planning applications: Events in neighbourhood, } \\
\text { Road works, Environmental projects }\end{array}$ \\
\hline \multirow[t]{2}{*}{ Services, Amenities, and Issues } & Information about opening times for parks, libraries, etc. \\
\hline & Information about cultural heritage sites \\
\hline \multirow[t]{2}{*}{ Social Issues and Information } & $\begin{array}{l}\text { To see and 'up to date' list of volunteers in my community } \\
\text { with skillset and reputation information }\end{array}$ \\
\hline & Datasets on citizen demographics \\
\hline Transport and Parking & $\begin{array}{l}\text { Data Journey planning information for people with } \\
\text { disabilities }\end{array}$ \\
\hline & Location of electric charging station for electric cars \\
\hline
\end{tabular}

sites - Issy-les-Moulineaux, and Prato - two sites that have a focus on business and local budgeting scenarios, respectively. It is likely that the information needs across sites will develop further as each pilot site works to realise their scenarios by reference to the key open data that allows for effective collaboration between citizens and public administrators. 


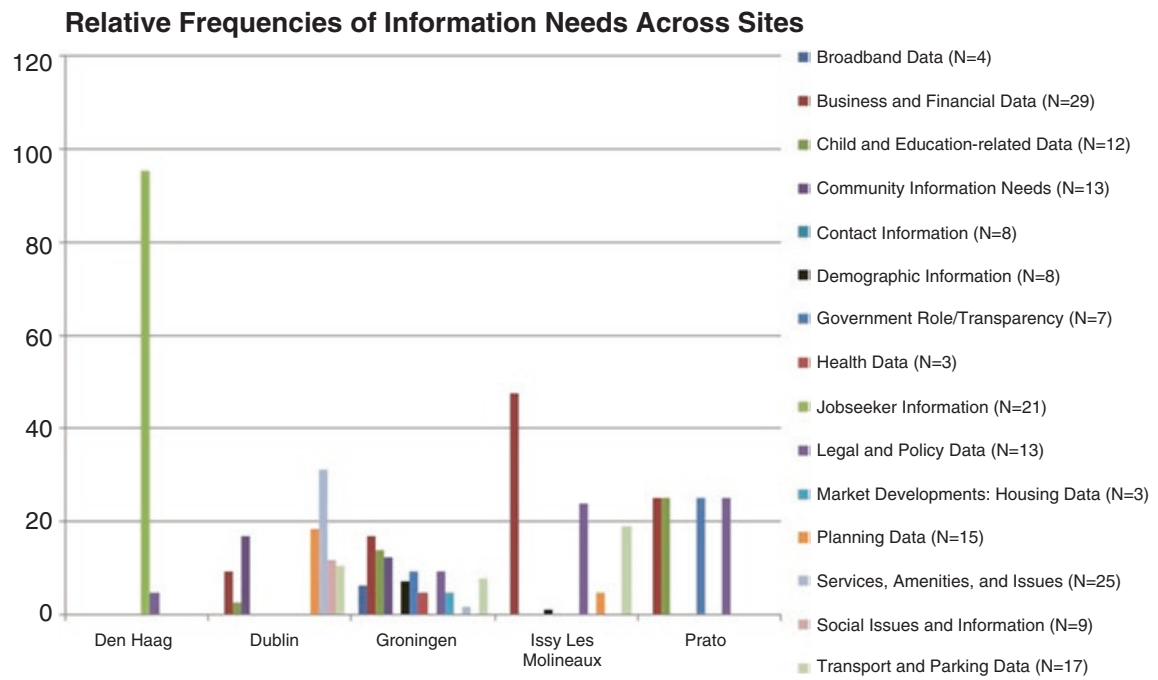

Fig. 4 Relative frequencies of information needs across sites

\section{Social-collaborative needs}

Table 4 presents the category analysis for social-collaborative needs across sites. Participants identified a range of social and collaborative needs, highlighting a number of forms of interaction for use over Open Data, as well as various considerations and capabilities which would enhance the impact and appeal of the platform. Participants highlighted the need for coaching and support, dialogue and discussion spaces; feedback, moderation and maintenance of these spaces; platform tool capabilities for interaction; varied forms of interaction over the data; and sharing and requesting data.

Analysis of the relative frequencies of social and collaborative needs (see Fig. 5) revealed that the Forms of interaction category accounted for a high percentage of the total social and collaborative needs in three pilot sites: Den Haag, Dublin, and Groningen. Coaching and support received the highest weighting in Issy-lesMoulineaux, and it also received a high weighting in Den Haag (along with Forms of interaction). Platform Tools and Capabilities for Interaction, which had the highest weighting in Prato, also received high relative weighting in Issy-les-Moulineaux and Dublin. Examples from the three categories highlighted above emphasise, for example, the need for flexibility of interaction: "there must be multiple modes" (Forms of interaction); the need for support tools to be in place to "help users to select the relevant data" (Coaching and support); and the ability to easily share data analyses with others: "To be able to easily share graphs and reports obtained by TET on social networks" (Platform Tool and Capabilities for Interaction).

3. Understandabilty, usability, and decision-making needs

Participants also used their scenarios to generate a set of understandabilty, usability, and decision-making needs (see Table 5). Categories of needs here include: 
Table 4 Sample social and collaborative needs across sites

\begin{tabular}{l|l}
\hline $\begin{array}{l}\text { Categories of social and } \\
\text { collaborative needs }\end{array}$ & Sample needs \\
\hline Coaching and Support & $\begin{array}{l}\text { Learn to use functionalities } \\
\text { Expert facilitation }\end{array}$ \\
\hline Contact Information & $\begin{array}{l}\text { Identify players in the field, personal contact } \\
\text { Personal contact regarding quality improvement }\end{array}$ \\
\hline Dialogue and Discussion Space & $\begin{array}{l}\text { Somewhere both PA and locals can see a shared } \\
\text { conversation } \\
\text { To rank suggestions from participants to the discussion }\end{array}$ \\
\hline Feedback & $\begin{array}{l}\text { A forum rich with feedback from politicians } \\
\text { Share feedback received from Public administrators }\end{array}$ \\
\hline Forms of Interaction & $\begin{array}{l}\text { To share graphics and visual reports obtained via SPOD/ } \\
\text { TET on Social Network } \\
\text { App on mobile phone }\end{array}$ \\
\hline Moderation and Maintenance & $\begin{array}{l}\text { To have a moderator associated to a discussion } \\
\text { To ensure group-specific communication }\end{array}$ \\
\hline Personalisation & $\begin{array}{l}\text { The ability to share my profile } \\
\text { To be able to moderate my portal }\end{array}$ \\
\hline Platform tool and capabilities for & $\begin{array}{l}\text { Notifications on the evolution of specific societal issues } \\
\text { (e.g. distribution of public subsidies) } \\
\text { Make data searchable }\end{array}$ \\
\hline interaction & $\begin{array}{l}\text { The ability to share data on social media To request new } \\
\text { datasets }\end{array}$ \\
\hline Sharing and requesting data & $\begin{array}{l}\text { A set of standardised forms and feedback response e.g. } \\
\text { forms and Disqus } \\
\text { Requests to follow a set format (e.g. when reporting a } \\
\text { flood - send a photo) }\end{array}$ \\
\hline Standardised Protocols &
\end{tabular}

certification tools; decision-making support tools; guidance and support tools; ability to visualise and personalising data, and data analysis and reporting tools.

A relative frequency analysis of Understandability, Usability, and Decisionmaking Needs (see Fig. 6) shows that, in four out of five pilot sites (Den Haag, Dublin, Groningen, and Prato), the category The Ability to Visualise and Personalise Data, generated the highest percentage of needs. This category included affordances which would help users to understand and use open data, by allowing a degree of flexibility and personal control over the way data is presented. Ideas in this category referred to the need, for example, to "Filter data to my neighbourhood/interests", to "Return all data about my local area and visualize", and "To be able to aggregate geographic data belonging to different data sets on a new map". Similarly, the category Data Analysis and Reporting Tools included a high percentage of overall needs across four pilot sites (Dublin, Groningen, Issy-les-Moulineaux, and Prato). This category includes a number of needs which are important for deeper analysis of open data, including: "Modelling tools that I can use with open data and citizens", "Data mining tools", and the need "To build in real time graphics and visual reports using Open Data". 
Relative Frequencies of Social and Collaborative Needs Across Sites

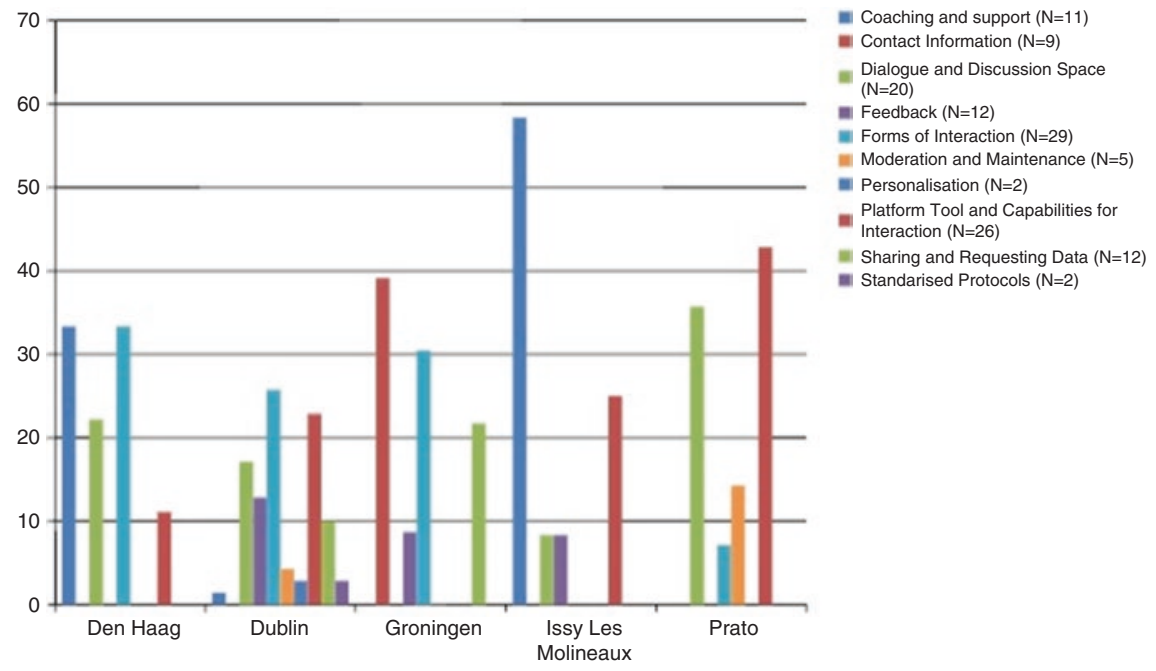

Fig. 5 Relative frequencies of social and collaborative needs across sites

Table 5 Sample understandability, usability, and decision-making needs across sites

\begin{tabular}{l|l}
\hline $\begin{array}{l}\text { Categories of understandability, } \\
\text { usability, and decision-making } \\
\text { needs }\end{array}$ & Sample needs \\
\hline Certification Tools & $\begin{array}{l}\text { To certify a published data set or report } \\
\text { To be able to demonstrate that a Data set or a report in my } \\
\text { possession has been produced by the platform }\end{array}$ \\
\hline $\begin{array}{l}\text { Data Analysis and Reporting } \\
\text { Tools }\end{array}$ & $\begin{array}{l}\text { Better labelling and contextual information on data } \\
\text { Data merge and wrangling tools }\end{array}$ \\
\hline Decision-Making Support Tools & $\begin{array}{l}\text { Mapping platform that gathers public opinion on local area } \\
\text { plans } \\
\text { A tool to discuss an issue and add data elements to } \\
\text { complement discussion }\end{array}$ \\
\hline Guidance and Support Tools & $\begin{array}{l}\text { Example of successful use app } \\
\text { Knowing which people use app }\end{array}$ \\
\hline Partner Websites & $\begin{array}{l}\text { Complementary information on other websites } \\
\text { A support to optimize functionalities }\end{array}$ \\
\hline Profiling & $\begin{array}{l}\text { Find similar entrepreneur profile on other open data } \\
\text { websites } \\
\text { Find comments which match with my own issues }\end{array}$ \\
\hline $\begin{array}{l}\text { The Ability to Visualise and } \\
\text { Personalise Data }\end{array}$ & $\begin{array}{l}\text { Filter data to my neighbourhood/interests Modifiable maps } \\
\text { and customisable dashboards }\end{array}$ \\
\hline
\end{tabular}


Relative Frequencies of Understandability, Usability, and Decisionmaking Needs Across Sites

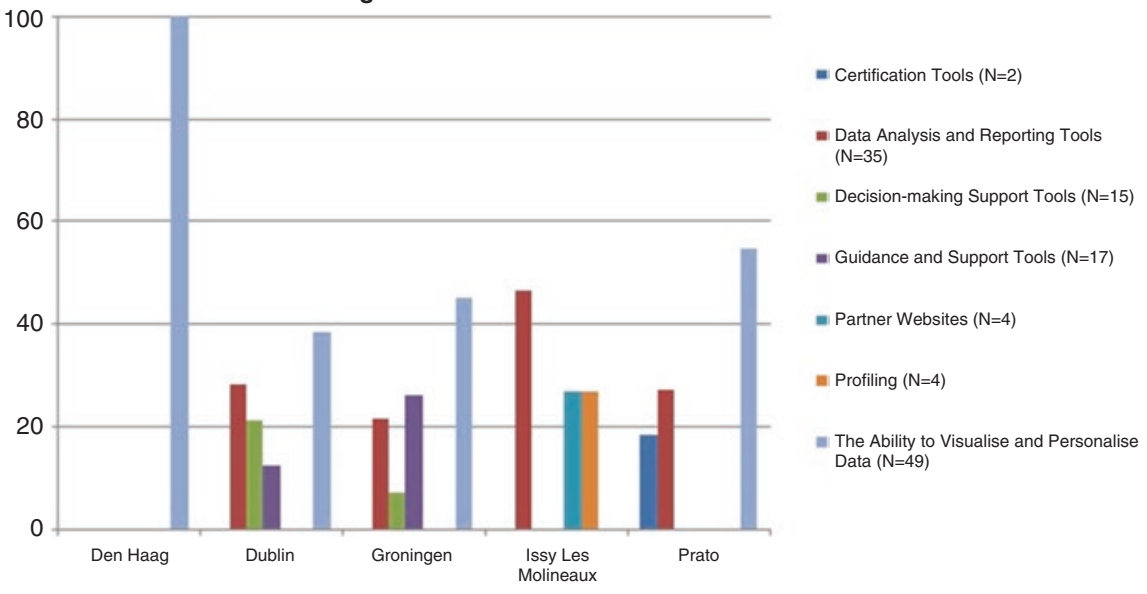

Fig. 6 Relative frequencies of understandability, usability, and decision-making needs across sites

\section{Discussion}

Research and innovation focused on the design of open data platforms has the potential to foster democratic processes by promoting transparency (Lourenço 2013; Dawes and Helbig 2010; Janssen 2011). A range of barriers have been identified that hamper effective service design and the full potential of open data platforms, including poor information quality, lack of usability and technical issues, limited organizational resources, and legislative challenges (Janssen et al. 2012; Attard et al. 2015; Meijer 2015a). A range of generic user requirements have been proposed to overcome barriers to effective open data platform design and service delivery (Lourenço 2013; Jaeger et al. 2012; Van Velzen et al. 2009), but the unique scenarios of usage and the unique needs of stakeholders are less often considered in the open data platform design process (Dahlander et al. 2009).

The current study reflects a contextualist approach to conceptualising transparency and open data platform design, drawing in particular on the collective intelligence scenario-based design ideas of stakeholders across five pilot sites in an effort to analyse barriers to accessing, understanding, and using open data, options to overcome these barriers, and the specific needs of open data platform users working across a variety of scenarios. This research was conducted as part of an EU innovation project, the Route-to-PA project. A primary goal of the project is the design of an open data collaboration platform that can be flexibly used by citizens and public administrators across a wide variety of usage scenarios that reflect a range of monitorial, deliberative, and participatory democracy activities. It was important for the platform design team to understand the varied political and social contexts where the open data platform is to be used, and the key needs of stakeholders. By using a 
combination of collective intelligence (Warfield 2006), scenario-based design (Caroll 2000) and agile user story (Cohn 2004) methods, we were able to achieve a number of goals in the current study. First, we received design input from a diverse range of representative stakeholders. Second, we identified needs and requirements of users that were grounded in an understanding of specific, relevant political and societal challenges they face. Third, we generated a set of user needs specified at a level of detail that allow for ongoing agile software development of specific functionalities.

Using these methods, we identified 12 categories of barriers to accessing, understanding, and using open data. These include two categories which relate to government and organisational barriers: Resistance to Open Data Initiatives, and Fear of Losing Control of Data. In relation to Resistance to Open Data Initiatives, stakeholders noted barriers such as, failure to understand the organisational benefits of releasing open data; resistance due to the fact that "It will take a lot of effort to convince people to use open data", and a refusal by politicians to transfer knowledge or power. Similarly, in relation to the category Fear of Losing Control of Data, stakeholders highlighted barriers such as: fear of loss of data ownership once data is released in an open format, and fear that the government will lose its reputation if it pursues the path of openness and transparency. Consistent with these findings, it has been argued that government departments will likely resist releasing precious information assets that define their political status and bargaining power vis-à-vis other government departments and stakeholders (Peled 2011). Increased cooperation across government departments may be essential in efforts to promote transparency into the future.

Notably, all EU countries represented in the current study are largely defined by systems of representative democracy, which means that passing over control to citizens to access and analyse open data relevant to political and societal issues may continue to be a challenge as governments seek to negotiate participatory democratic or networked governance arrangements. At the same time, a range of options were proposed in response to these two categories barriers, including: increased effort in providing enjoyable and intuitive interfaces for local government staff to publish data as open data; celebrating open data innovation leaders in organisations to highlight the importance and value of their work; and providing information, training and education for all government agencies on the benefits of an open data portal.

Stakeholders identified two additional categories of barriers that are closely related to the government and organisational barriers described above, specifically, Privacy and Security and Conflict and Cooperation. In the Privacy and Security category, which Janssen and colleagues call the legislation barriers (Janssen et al. 2012), stakeholder's barrier statements highlighted issues such as: personal information accessed by the public can lead to data protection infringement; some data are commercially sensitive; and privacy and security may be compromised by conflicting roles and interests between politicians, management, and the public. Options for overcoming barriers in this category included: efforts to organise multi-level training on how to use data safely; initiatives showcasing good practice; and research 
examining how potentially sensitive data is used in an open environment in other countries.

In relation to the Conflict and Cooperation category, stakeholders generated barriers such as: conflict and lack of progress in the development of open data initiatives due to contrary interests; and lack of cooperation between government and public. Stakeholders suggested a range of options in response to this category of barriers, including efforts to introduce procedures to standardise/simplify data release; establish the practice of asking and having to justify "why not" around data release; and establish a data review board for an organisation to help individual public administrators with data release decisions.

The four categories of barriers discussed above all relate to government and organisational issues. Moving beyond these types of barriers, stakeholders also identified a number of categories of barriers which were more closely related to technical or resource issues. This is in line with the findings of Attard et al. (2015), and Janssen et al. (2012), who identified technical barriers as impediments to open data platform service delivery. In the current study, five categories of barriers emerged that were related to technical, data, and resource issues, specifically: Data Applications; Data Management/Policies; Data Quality, Accessibility, and Usability; Technical, Infrastructure and Resources; and Cost.

With regard to Data Applications, stakeholders highlighted barriers such as: lack of examples available for smart use of open data; and issues with the effectiveness of research tools, whereby queries are not tailored to real user's needs. Options generated in response to barriers in this category included: making a connection with education, to provide examples; and providing a more complete platform for better searchability of data.

Stakeholders also generated a significant number of barriers focused on data management and policies. Barriers in this category included: lack of information about the circumstances of data production; and lack of data maintenance. As a means to overcoming such barriers, stakeholders suggested the implementation of "good information practices" within public bodies. It was also suggested that the regulation of transparency activities, incentivised with rewards, would address barriers in this category.

Stakeholders also generated a related category of barriers: Data Quality, Accessibility, and Usability. This category represented the largest set of ideas across sites and includes barriers such as: data may be published but not easily found; data does not have a user-friendly format; and insufficient data descriptions. In response to these barriers, stakeholders suggested the involvement of users in the development of data platforms, and that clear descriptions should provide information about when the data was collected, how it was collected, and by whom.

These barriers resonate with data challenges identified by other scholars, including challenges associated with exploration, extraction, and formatting, cleaning, and ungrounding (or rawification) of data (Denis and Goeta 2014). Similarly, Bertot et al. (2008) note that e-government services are often limited by challenges associated with organisation, structure, search, metadata, and other factors. 
As well as data-specific barriers, stakeholders generated a category of barriers relating to Technical, Infrastructural, and Resource Issues. Barriers in this category include: data is spread over different organisations and departments; and inadequate institutional capacity can often limit the provision of data services, the development of standards, and the provision of necessary expertise. Stakeholders suggested that pooling of public sector resources, and better curation and maintenance of data quality, could help to alleviate barriers in this category.

The final technical or resource based category developed by stakeholders related to Cost. Stakeholders noted that a lack of adequate finances often negatively impacts the sustained collection, and sharing of open data. Similarly, stakeholders noted that the cost of accessing open data can often be prohibitive. In order to address these, and other cost-related barriers, stakeholders suggested that data creation should be driven by user demand. Stakeholders also suggested that the creation of funds to commercialise open data projects could alleviate some of the cost-related barriers.

Finally, three categories relating to training and engagement issues were developed by stakeholders. These categories are as follows: Citizen Engagement; Skills and Training; and Motivation. These categories are in line with what Janssen et al. (2012) call use and participation.

Specifically in relation to Citizen Engagement, stakeholders referred to barriers such as: minimal publicity of open data leading to lack of awareness of its existence; and failure by government departments to advertise that data is available to the public. Stakeholders proposed a range of options to overcome these barriers including, for example, promotion programmes aimed at the public to create not just awareness of data availability but also uses and benefits of open data; and the opening of channels for the public to communicate with governments. In relation to Skills and Training, stakeholders noted a number of barriers relating to lack of open data skills on the part of data providers and users, including both public administrators and citizens. For example, stakeholders noted that inadequate technical expertise to produce data in a usable format is a significant barrier to usage, as well as users' lack of skills to process data and translate open data into information. In response to these and similar barriers, participants suggested that government agencies should be provided with training on the benefits of an open data portal, and that platforms provide detailed frequently asked questions sections to assist users.

Finally, in relation to Motivation, stakeholders referred barriers such as: open data publishing is often not perceived as a priority by administrators, and the lack of understanding of the benefits that Open Data can offer. In order to overcome these barriers, stakeholders suggested options including: promotion of the benefits of an open data portal, the provision of good examples, and publishing data that is identified by users as relevant and engaging.

As noted, overall, barriers associated with Data quality, Accessibility, and Usability represented the largest portion of the total set of barriers generated across sites. Similarly, barriers associated with both Data Management and Policies and Technical, Infrastructure and Resources represented a large portion of the total number of barriers generated. This is consistent with previous research which has highlighted poor information quality, lack of usability and technical issues, limited 
organizational resources and budget as major barriers to achieveing the full potential of open data platforms (Janssen et al. 2012; Attard et al. 2015; Meijer 2015a) .

Analysis of the relative frequencies of barriers across sites provided insight into the relative weight stakeholders in each pilot site placed on the various barrier categories. For example, the high frequency of barriers in the Data Quality, Accessibility, and Usability category overall reflected the fact that this category accounted for a high percentage of total barriers generated by stakeholders in Prato, Groningen, Issy-les-Moulineaux, Den Haag, and Dublin. Barrier statements in this category were also phrased similarly across sites. For example, "Information is not presented in a user friendly manner" (Den Haag); "Lack of user-friendly file-formats" (Dublin); and "Data is published but cannot be found and does not have a userfriendly format" (Groningen).

However, a number of differences were also observed across sites. For example, the relatively stronger focus on data application barriers in Prato and Den Haag could reflect the fact that both of these pilot sites and stakeholder groups are relatively new to working with open data platforms. By contrast, Dublin, which has an active open data platform, emphasised less data application barriers but highlighted more barriers linked to skills and training. It may be that certain barriers and needs (e.g., associated with the skilled used of platforms) will only arise after stakeholders have had experience working with an evaluating existing platforms and services. A key goal of the Route-to-PA project is to build upon existing platforms and provide coaching and training in the use of key functionalities, working directly with stakeholders in each pilot site. Work is ongoing to evaluate user experience of key functionalities and the specific training needs that will be required as new platform users are introduced to the platform. It is noteworthy that all pilot sites in the current study emphasised technical, infrastructure, and resource barriers. Overcoming these barriers may be essential to ensuring sustainable inputs in terms of quality data, iterative design of platforms to enhance functionalities, and ongoing skills training to increase the data competencies and collaboration skills of stakeholders and open data platform users engaged in governance networks.

The different focus across sites is also evident in the absence of categories of barriers in certain pilot sites. For example, Skills and Training is represented in all pilot sites except Prato. Similarly, neither Resistance to Open Data Initiatives nor Fear of Losing Control of Data are represented in the barrier categories in Den Haag or Prato. The lower representation of barriers across categories in Prato is not surprising, given that $79 \%$ of their total barriers fell into the three data-related categories: Data Quality, Accessibility, and Usability; Data Management/Policies; and Data Applications. This suggests that stakeholders in Prato are primarily focused on data-related barriers at this stage of their work together, and may not yet have encountered organisational or training related barriers to the extent that other pilot sites have.

There were also differences across pilot sites in the number and types of options generated in response to barriers. For example, while Citizen Engagement received a high percentage of generated options in Groningen (e.g. ask citizens which information they find useful) and Issy-les-Moulineaux (e.g. allow citizens to make rec- 
ommendations on the mode of data collection, the quantity of data and the presentation format), it received relatively less attention in the other sites. Also, whereas options in Dublin were spread across all categories, options were more focused on a smaller set of specific categories in Den Haag and Prato. This suggests that stakeholders in Den Haag and Prato, at least in their initial evaluation of the problem situation, have identified a strong need for options in response to a select number of barrier categories. Similarities and differences across sites provide useful insights for the design team in terms of the possible focus of attention across pilot sites when open data platform innovations are fully operational. They also highlight key areas where flexible design of platform features needs to be combined with broader strategies of political and social engagement with stakeholders and user groups to ensure uptake and continued use of open data platform innovations.

Each pilot site in the current study focused on unique scenarios that reflect local political and social priorities and thus stakeholders in each site had unique needs. This was clearly reflected, in the first instance, in the range of open data information needs across sites. For example, while the scenario in Den Haag focused on employment and opportunity creation, resulting in a high proportion of jobseekers information needs, the Dublin scenario, which focused on community engagement and planning, generated information needs across a much wider range, including community, planning, services, amenities, business, and education information. It is likely that the information needs across sites will develop further as each pilot site works to realise their scenarios and promote effective collaboration between citizens and public administrators.

More generally, essential for the future success of open data portals is that more varied high-quality open data is made available to stakeholders in an increasingly accessible, understandable and usable manner. Societal challenges or problems, including those that stakeholder focused on in the current study, are invariably complex. A key goal of networked governance is to enhance our overall capacity to collaboratively resolve societal problems. However, as noted by Warfield (2006), understanding societal problems always involves an effort to identify how problems in the problem situation interact. Failure to recognise potential interactions between problems in the problem situation can result in unexpected and often undesirable outcomes. To the extent that networked governance arrangements involve collaboration over open data in efforts to resolve societal problems, having access to sufficiently varied, usable and understandable open data matched to the complexity of the problematic situation will be a core requirement of effective governance into the future. Ongoing work by the Route-to-PA team has involved profiling the extent to which open data is available, matched to, and useful for, the scenarios of interest to stakeholders in each pilot site. This profiling of data is being used to feedback to public administrators and key data providers to highlight some of the key gaps in the data.

Stakeholders across pilot sites in the current study also highlighted a range of social and collaborative needs, in particular, the need for different forms of interaction over open data, including dialogue and discussion spaces, moderation and maintenance of these spaces, feedback, sharing and requesting data, and also coaching 
and support in the use of social-collaborative affordances. To date, the Route-to-PA team has designed a number of key social-collaborative affordances, including a dialogue and collaboration platform that allows for sharing and discussion of data visualisations, awareness of network connections and levels of engagement between users collaborating on shared projects, and the capacity to create dedicated collaboration spaces focused on specific issues.

Furthermore, the current study identified a variety of understandability, usability, and decision-making needs of users, including the need for certification tools, guidance and support tools, data visualisation and personalisation tools, and data analysis and reporting tools. The ability to search, filter, aggregate, visualise, modify, customise, and analyse data were identified as central needs across pilot sites. More advanced data analysis and reporting tools were also seen as central for decision-making, including data mining tools, modelling tools, metadata tools, data merging tools, data wrangling and labelling tools, among others. A key challenge for the Route-to-PA design team moving forward is to design affordances that support understandability, usability, and decision-making needs in a way that both citizens and public administrators can readily learn to use without advanced training in statistical data analysis techniques. This presents a major challenge as a reasonably high level of data competency may be needed to match the complexity of the societal issues collaborative groups are working on. One potential solution to this challenge is to design collaborative groups that include stakeholders with a range of skills, including a sub-group who specialise in more advance data analysis and visualisation work that supports the deliberation and decision-making of the larger team.

\section{Limitations and Directions for Future Research}

There are a number of limitations to the current study. First, while reflecting the different scenarios and contexts of usage identified as the starting point for the Route-to-PA project, there was considerable variation in the stakeholders who participated in the collective intelligence sessions across the different sites in the current study. For example, Issy-les-Moulineaux was focused on a local enterprise development scenario and thus the major citizen group in this context was stakeholders in the business sector. The study results, and the range of information needs identified across sites in particular, also vary as a function of the scenario and the participants in the scenarios that stakeholders in each pilot site were using to support idea generation at their respective workshops. At the same time, these scenarios reflected the types of problems that stakeholders in each pilot site were seeking to address, and thus the variation across sites is consistent with our contextual approach to open data platform design. Future research should seek to examine the barriers, options and needs of different user groups across a range of different scenarios, to further our understanding of the range of barriers, options, and needs that will need to be considered in the future, in efforts to design 
increasingly flexible and adaptable open data platforms that support the goals of stakeholders across a range of different scenarios of usage. We speculate that perceived barriers to accessing, understanding, and using open data, and options to overcome these barriers, may show greater similarities across different contexts, when compared with the range of information, social-collaborative, and decisionmaking needs of users, as these barriers may reflect underlying political and socialorganisational challenges that are fundamental to the broader societal challenge of supporting transparency and collaboration over open data. Furthermore, our conclusions regarding the specific needs of users are a function of the specific methods we used, and future research should seek to combine our collective intelligence scenario-based design methods with other user-centered methodologies to provide more insight into the specific barriers, options, and needs of open data platform users. For example, the use of remote user testing may be particularly useful in the iterative design of open data platforms as they evolve and develop further.

\section{Conclusions}

In line with the approach adopted in the current study, Ojo and Mellouli (2016) note that governments are increasingly engaging private sector organizations, civil society and citizens to tackle complex policy challenges across a variety of networked governance arrangements. Although evidence suggests that networks of non-state actors are equally as important as networks of state actors in terms of their contribution to governance outcomes (Bodin and Crona 2009), networked governance implies the need to develop a shared understanding of problems and solutions to problems (Huppé et al. 2012). This implies the need for a collective intelligence approach to the design of platforms that facilitate the deliberation of diverse governance networks over open data, and the co-creation of policies and projects that help to resolve societal problems, increase trust in government, and empower increasingly effective networked governance arrangements into the future.

As noted by Ojo and Mellouli (2016), the efficacy of governance networks is contingent on the inclusion of citizen in the networks, and mobile social-media platforms could constitute a key infrastructure for enabling citizen participation in this regard. However, based on their case study analyses, they also note that these networks are still largely steered by government and it remains important that governments initiate and demonstrate deep commitments to partnerships with citizens for collaborative governance networks to be effective. Ojo and Mellouli (2016) note that government is ultimately responsible for building trust with partners and are accountable for the overall outcome of the networked governance arrangement. This implies ongoing investment and iterative design, innovation and experimentation with key infrastructures that may support networked governance. Considering the specificity of the key understandability, usability, and decision-making needs identified in the current study, it is clear that governments and citizens need to 
work with social scientists and technology experts to design open data platforms that include a range of data analysis and decision-making affordances that support collaborative societal problem solving and policy development. This needs to be coupled with appropriate training in the use of these affordances. Based on their case study analyses, Ojo and Mellouli (2016) highlight the need to effectively motivate citizen participation in governance networks and align the divergent views of the different actors collaborating in the network. From a contextualist perspective, the collective intelligence scenario-based design thinking of stakeholders in the current study highlights that motivating citizens may be contingent on meeting their needs. This implies designing a socio-technical infrastructure that supports their social-collaborative and decision-making needs, which will be critical to sustain motivation in the use of the platform.

Consequently, based on the outcomes from our study and related literature, we conclude that: (1) the nature of barriers and needs of stakeholders can vary significantly from one context to another and this needs to be considered in the development of open data platforms that are designed explicitly for use across several local authorities or contexts; (2) the iterative use of collective intelligence scenario-based design methods employed in eliciting barriers, options and needs from different stakeholders could be an effective approach for engaging stakeholders in the design of open data platforms into the future, particularly if it can be effectively combined with other user-centered methods; (3) continued engagement of stakeholders in the design and development of open data platforms is contingent on the support provided by local authorities working with the stakeholders.

\section{Appendix 1}

\footnotetext{
Sample scenarios

Entrepreneur Annie is interested in starting a locally based café/food business and would like to connect with public administrators and potential customers to find out if there is a demand for this new business, what kind of premises or permissions she might need, what supports are available and to connect with other people who might partner/work with her in starting this business. She would like to use technology to build local social networks to connect with her business peer network and build a local customer base.
}

Civic Joe is part of the civic hacker community and a member of an active citizen group. He is a keen advocate for social equality and feels that citizens need a more participatory democracy to create a better society for all. He is interested in open data as a means of opening access to public information and promoting transparency. He wants to be able to interact with public data to understand how public decisions are made, to give his views in an easy and transparent way and receive feedback on them from public administrators who area leading local projects, so that he feels he has been part of the decision and policy making process. Joe also wants to be able to share ideas and data with other citizen groups, with a view to collaborating on projects and common goals. 


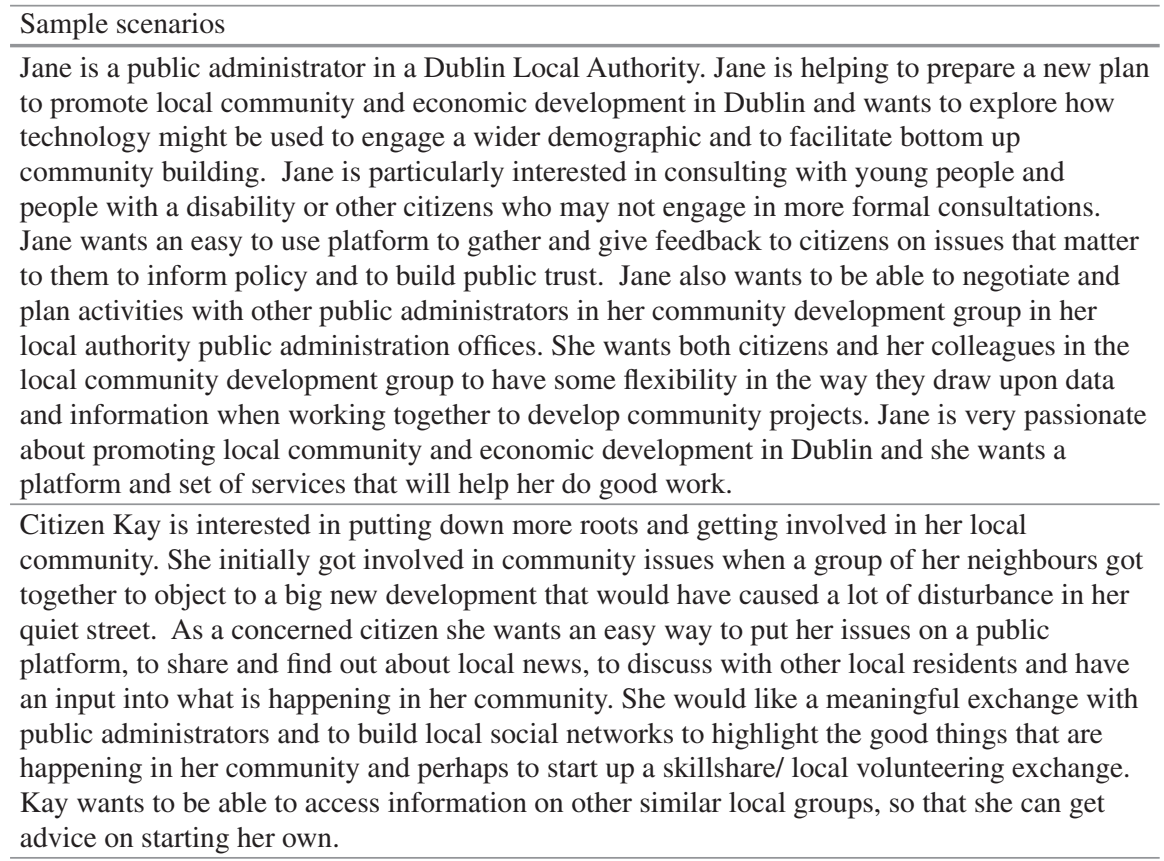

\section{References}

Alexopoulos C, Zuiderwijk A, Charapabidis Y, Loukis E, Janssen M (2014) Designing a second generation of open data platforms: integrating open data and social media. In: International conference on electronic government, Springer, Berlin/Heidelberg, pp 230-241

Alberts, H. (1992). Acquisition: Past, present and future. Paper presented at the meeting of the Institute of Management Sciences and Operations Research Society, Orlando, FL

Ashby WR (1958) Requisite variety and its implications for the control of complex systems. Cybernetica 1(2):1-17

Attard J, Orlandi F, Scerri S, Auer S (2015) A systematic review of open government data initiatives. Gov Inf Q (in press)

Bannister F, Connolly R (2011) The trouble with transparency: a critical view of openness in egovernment. Policy \& Internet 3(1):158-187. doi:10.2202/1944-2866.1076

Bertot JC, Jaeger PT, McClure CR (2008) Citizen-centered e-government services: benefits, costs, and research needs. In: Proceedings of the 2008 international conference on digital government research, Digital Government Society of North America, pp 137-142

Bodin Ö, Crona BI (2009) The role of social networks in natural resource governance: what relational patterns make a difference? Glob Environ Chang 19(3):366-374

Broome BJ, Cromer IL (1991) Strategic planning for tribal economic development: A culturally appropriate model for consensus building. International Journal of Conflict Management 2:217-234

Broome BJ, Fulbright L (1995) A multi-stage influence model of barriers to group problem solving. Small Group Res 26:25-55

Broome BJ, Chen M (1992) Guidelines for computer-assisted group problem-solving: Meeting the challenges of complex issues. Small Group Res 23:216-236 
Cappelli C, Engiel P, De Araujo RM, Cesar J, Leite P (2013) Managing transparency guided by a maturity model. In: 3rd global conference on transparency research, HEC, Paris, France, 24-26 October 2013, pp 1-17

Caroll J (2000) Five reasons for scenario-based design. Interacting with Computers 13:43-60

Christakis AN (1987) Correspondence: Systems profiles. Systems Research 4(1):53-58

Coke JG, Moore CM (1981) Coping with a budgetary crisis: Helping a city council decide where expenditure cuts should be made. In: Burks SW, Wolf JF (eds) Building city council leadership skills: A casebook of models and methods. National League of Cities, Washington, DC, pp 72-85

Cohn M (2004) User stories applied for Agile software development. Addison-Wesley, Boston

Dahlander L, Fredriksen L, Rullani F (2009) Online Communities and Open Innovation. Ind Innov 15(2):115-123

Dawes S, Helbig N (2010) Information strategies for open government: challenges and prospects for deriving public value from government transparency. Electron Gov 6228:50-60

Deloitte (2013) Market assessment for public sector information. Written for UK, Department for Business, Innovation and Skills

Denis J, Goëta S (2014) Exploration, Extraction and "Rawification " The Shaping of Transparency in the Back Rooms of Open Data. In: Neil Postman Graduate Conference. New York, pp 1-8

Dwyer C, Hogan M, Harney O, O'Reily J (2014) Using interactive management to facilitate a student-centered conceptualisation of critical thinking: a case study. Educ Technol Res Dev 62(6):687-709

Fox J (2007) The uncertain relationship between transparency and accountability. Dev Pract 17(45):663-671. doi:10.1080/09614520701469955

Feeg R (1988) Forum of the future of pediatric nursing: Looking toward the 21st century. Pediatric Nursing 14:393-396

Ghaus-Pasha A (2007) Governance for the millenium development: core issues and good practices. Building

Greiner A, Isaac A, Iglesias C, Laufer C, Guéret C, Stephan EG, Kauz E, Atemezing GA, Bittencourt II, Almeida JP, Carrasco MT, Archer P, Albertoni R, Purohit S Córdova Y (2015) Data on the Web best practices - W3C working draft 25 June 2015. Retrieved from http://www. w3.org/TR/2015/WD-dwbp-20150625/

Grimmelikhuijsen SG, Welch EW (2012) Developing and testing a theoretical framework for computer-mediated transparency of local governments. Public Adm Rev 72(4):562-571. doi:10.1111/j.1540-6210.2011.02532.x

Groarke JM, Hogan MJ (2016) Enhancing wellbeing: An emerging model of the adaptive functions of music listening. Psychology of Music 44(4):769-791

Hayes SC, Hayes LJ, Reese HW (1988) Finding the philosophical core: a review of Stephen C. Pepper's world hypotheses: a study in evidence. J Exp Anal Behav 1(1):97-111

Habermas J (1962) The structural transformation of the public sphere (1962, trans: Cambridge Massachusetts, 1989, MIT Press)

Heald D (2006) Varieties of transparency. Proceedings-British Academy 25-43. doi:10.5871/ bacad/9780197263839.003.0002

Hilgers D, Ihl C (2010) Citizensourcing: applying the concept of open innovation to the public sector. Int J Public Participation 4(1):67-88

Hogan MJ, Johnston H, Broome B, McMoreland C, Walsh J, Smale B et al (2015) Consulting with citizens in the design of wellbeing measures and policies: lessons from a systems science application. Social Indicators Research 123(3):857-877

Jaeger P, Bertot JC, Shilton K (2012) Information policy and social media: framing governmentcitizen Web 2.0 interactions. In: Reddick CG, Aikins S (eds) WEb 2.0 Technologies and Democratic Governance. Political, policy and management implications, Springer, New York, pp 11-25

Janssen K (2011) The influence of the PSI directive on open government data: an overview of. Gov Inf Q 28:446-456 
Janssen M, Charalabidis Y, Zuiderwijk A (2012) Benefits, adoption barriers and myths of open data and open government. Inf Syst Manag 29(4):258-268

Keever, D. B. (1989, April). Cultural complexities in the participative design of a computer-based organization information system. Paper presented at the International Conference on Support, Society and Culture: Mutual Uses of Cybernetics and Science, Amsterdam, The Netherlands

Lee G, Kwak Y (2012) An open government maturity model for social media-based public engagement. Gov Inf Q 29(4):492-503

Lourenço RP (2013) Open government portals assessment: a transparency for accountability perspective. Lecture Notes in Computer Science (including Subseries Lecture Notes in Artificial Intelligence and Lecture Notes in Bioinformatics), 8074 LNCS, 62-74. doi:10.1007/ 978-3-642-40358-3-6

Mei CS, Dewan SM (2014) Towards conceptualizing information transparency and its role in internet consumers' concerns: a literature review

Meijer A (2009) Understanding modern transparency. Int Rev Adm Sci 75(2):255-269. doi:10.1177/0020852309104175

Meijer A (2015a) E-governance innovation: barriers and strategies. Gov Inf Q 32:198/206

Meijer A (2015b) Government transparency in historical perspective: from the ancient regime to open data in The Netherlands. Int J Public Adm 38(3):189-199. doi:10.1080/01900692.2014 .934837

Ojo A, Porwol L, Waqar M, Stasiewicz A, Osagie E, Hogan M, Harney O, Ahmadi-Zeleti F (2016) Realizing the innovation potentials from open data: Stakeholders' perspectives on the desired affordances of open data environment, 17th IFIP working conference on virtual enterprises, Porto, Portugal, 3-5 October 2016, Springer

Ojo A, Mellouli S (2016) Deploying governance networks for societal challenges. Gov Inf Q. doi:10.1016/j.giq.2016.04.001

Peled A (2011) When transparency and collaboration collide: the USA open data program. J Am Soc Inf Sci Technol 62(11):2085-2094

Pepper SC (1942) World hypotheses: a study in evidence. University of California Press

Piotrowski S, Conference G, Sasaki D (2011) Conceptualizing the Quality of Transparency Paper prepared for the 1,0-27

RezaeiZadeh M, Hogan M, O’Reilly J, Cunningham J, Murphy E (2017) Core entrepreneurial competencies and their interdependencies: insights from a study of Irish and Iranian entrepreneurs, university students and academics. Int Entrep Manag J 13(1):35-73

Rosson MB, Carroll J (2002) Scenario-based design. In: Jacko J, Sears A (eds) The humancomputer interaction handbook: fundamentals, evolving technologies and emerging applications. Lawrence Erlbaum Associates, Mahwah, pp 1032-1050

Sandoval-Almazan R, Gil-Garcia JR (2012) Are government internet portals evolving towards more interaction, participation, and collaboration? Revisiting the rhetoric of e-government among municipalities. Government Information Quarterly 29:72-81

Sato T (1979) Determination of hierarchical networks of instructional units using the ISM method. Educational Technology Research 3:67-75

Van Velzen L, Van der Geest T, Ter Hedde MD (2009) Requirements engineering for e-Government services: a citizens-centric apporach and case study. Gov Inf Q 26:477-486

Warfield JN (1994) Science of generic design: managing complexity through systems design. Iowa State Press, Ames

Warfield JN (2006) An introduction to systems science. World Scientific, Singapore

Zuiderwijk A, Janssen M (2014) Open data policies, their implementation and impact: a framework for comparison. Gov Inf Q 31:17-29

Michael Hogan is a senior lecturer and researcher at NUI, Galway, Ireland. His research foci include individual, social and technology factors contributing to adult learning, motivation, and collaborative performance. He is a co-director of the Structured $\mathrm{PhD}$ in Perception, Cognition and Action, co-director of the Structured $\mathrm{PhD}$ in Learning Sciences, and a co-leader of the Health and Wellbeing theme at the Whitaker Institute for Innovation and Social Change, NUI, Galway. 
Dr. Adegboyega Ojo is Senior Research Fellow at the Insight Centre for Data Analytics, National University of Ireland Galway (NUIG). He leads the E-Government Group at Insight Centre, serves as Adjunct Lecturer at the College of Engineering and Informatics. His current research interests include data driven innovations in government, Open data policies and Infrastructures, data analytics and governance of smart cities. He is member of the Editorial Boards of the Government Information Quarterly and International Journal of Public Administration in the Digital Age.

Owen Harney is a PhD candidate (Learning Sciences) at the School of Psychology, NUI Galway. $\mathrm{His} \mathrm{PhD}$ research focuses on the integration of systems science methodologies into educational contexts. Outside of his PhD research, Owen has applied his knowledge of systems science and collective intelligence methodologies in a wide variety of research and organisational contexts, including: collaborative learning, e-governance, chronic pain, personalised nutrition, and citizen engagement.

Erna Ruijer is a postdoctoral researcher at the Utrecht School of Governance in the Netherlands. Her research focuses on open data, government transparency, open government and government communication.

Albert Meijer is a Professor of Public Innovation at the Utrecht School of Governance in the Netherlands. His research focusses on e-government, government transparency, co-production in the public sector and public innovation.

Jerry Andriessen is a senior scientist and research director of Wise \& Munro learning Research, The Hague, Netherlands. Wise \& Munro participates in many innovative European projects, on technology, open data, collaboration, primary education, and cybersecurity. These projects add societal relevance to their scientific implications. Jerry has more than 25 years of experience in uses of technology for support of learning and collaboration in various settings. His current interest is in the qualitative interpretation of discourse and action, including the roles of emotions.

Mirjam Pardijs is an independent educational scientist. She is co-director of Wise \& Munro Learning Research, the Hague, Netherlands. She specialises in the design, coaching, and interpretation of collaborative learning in educational and professional contexts. Her main interests are narratives as a tool for learning, appropriation of technology, and the role of pedagogical support for innovation in learning settings.

Paolo Boscolo gained a Masters degree in Electronics Engineering in 1986. In 1992 he joined the Comune di Prato as head of the Telecommunications group. Is new responsible for the general coordination of the ICT service and for co-funded project in ICT field. During last 10 years has been charged for the management of advanced eGovernment projects for the Prato City Council. $\mathrm{He}$ is currently responsible for the definition of the Prato Smart City Plan. He's the responsible for Route-to-PA project operations at Comune di Prato.

Elena Palmisano received a degree in Civil Engineering in 1988 and a Ph. D. in Methods and Technologies for Environmental Monitoring in 1994 at the University of Florence (Italy). She works as a consultant with PIN Scrl (a public/private Consortium managing the University of Florence site in Prato) and with the Municipality of Prato. She has taken part in many regional, national and EU projects in the field of innovation technology, ICT applications in different contexts, such as infomobility, e-government, cultural heritage and education. She is currently collaborating with the Municipality of Prato in two H2020 projects: Route-to-PA (GA N. 645860), where she acts as community manager in the pilot activity, and City.Risks (GA N. 653747) where she contributes to the managemnt of dissemination activities. With PIN S.c.r.l. she is also involved in the definition of the guideline for the development of the Smart City plan in Prato.

Matteo Satta is an international Political Sciences graduate in Turin (Italy), he is a senior project manager that has always been involved, between France and Italy, in the field of R\&D and 
Innovation (EU and International level) with a particular focus on its valorisation and exploitation. Since 2005, he has contributed to the management and the development of various European projects, such as e-Photon/ONe, the Researchers' Night in Turin (Italy), RADICAL, OTN, ECIM, Citadel... on the Move and ROUTE-TO-PA, and IPR Licensing programs, such as MPEG Audio (MP3) and DVB-T. He is today EU Project Manager in Issy Média, a semi-public company of the City of Issy-les-Moulineaux, specializing on Smart City subjects and projects with a particular interest in citizens' participation, Living Lab, Open Data and Smart Mobility.

Jonathan Groff is a researcher in cognitive psychology. He is currently working at the National Center for Scientific Research (CNRS), Paris. He is interested in human computer interactions and multimedia information processing (in the field of education and in the transport sector). He carried out work designed to evaluate the effect of attentional cueing and interactive animation on comprehension, using an eye tracking approach. He developed a pictographic system that aims to promote the quick understanding of emergency announcements in multimodal hubs. Currently, he is studying cognitive processes in collaborative design situations.

Michael Baker is a Research Director (tenured Research Professor) in psychology and language sciences, of the Centre National de la Recherche Scientifique (CNRS). He currently works in the Social and Economics Science Departement of Telecom ParisTech, the French National Telecommunications Engineering School. His research aims to analyse and model the processes of knowledge elaboration in dialogues produced in learning and work situations, focussing on argumentation and the role of technological mediation. Michael Baker recently published the following book, with Baruch Schwarz: "Dialogue, Argumentation and Education: History, Theory and Practice" (Cambridge University Press, New York, 2017).

Françoise Détienne is research director at CNRS, Paris. Her research in cognitive ergonomics focusses on collaboration, design, creativity and online communities as well as on the role of socio-technical systems. She is associate editor of International Journal of Human Computer Studies, and member of the editorial board of Interacting With Computers and CoDesign.

Dr. Lukasz Porwol is a Postdoctoral Researcher and deputy unit leader at Insight Centre for Data Analytics (formerly known as DERI), National University of Ireland, Galway. At Insight Centre for Data Analytics, his research work focuses on leveraging social media, games and mobile technologies to support effective dialogue between citizens and decision-makers. His background combines solid engineering and scientific knowledge (MSc in Computer Science and Engineering in Information Technologies) with good management and PR skills.

Vittorio Scarano is Computer Science Associated Professor at the Dipartimento di Informatica of Università di Salerno. He is coauthor of more than 150 papers in journals and international conferences (with reviews) at IEEE, ACM etc. and was advisor (or co-advisor) of $12 \mathrm{PhD}$ thesis in Computer Science at the University of Salerno. His research is mainly focussed on open data, distributed, parallel and cooperative systems, and to their applications in the fields of collaborative learning and virtual interactive environments (Cultural Heritage).

Delfina Malandrino is an Assistant Professor at the Dipartimento di Informatica of the University of Salerno. Her research activities mainly focus on: privacy, distributed systems, collaborative systems, social networking, privacy, social network analysis, green computing. 